\title{
Seasoanl and Long-run fractional Integration in the Industrial Production Indexes of some Latin American Countries
}

Citation for published version (APA):

Candelon, B., \& Gil-Alana, L. A. (2004). Seasoanl and Long-run fractional Integration in the Industrial Production Indexes of some Latin American Countries. Journal of Policy Modeling, 26, 301-313. https://doi.org/10.1016/j.jpolmod.2004.03.008

Document status and date:

Published: 01/01/2004

DOI:

10.1016/j.jpolmod.2004.03.008

Document Version:

Publisher's PDF, also known as Version of record

\section{Please check the document version of this publication:}

- A submitted manuscript is the version of the article upon submission and before peer-review. There can be important differences between the submitted version and the official published version of record.

People interested in the research are advised to contact the author for the final version of the publication, or visit the DOI to the publisher's website.

- The final author version and the galley proof are versions of the publication after peer review.

- The final published version features the final layout of the paper including the volume, issue and page numbers.

Link to publication

\footnotetext{
General rights rights.

- You may freely distribute the URL identifying the publication in the public portal. please follow below link for the End User Agreement:

www.umlib.nl/taverne-license

Take down policy

If you believe that this document breaches copyright please contact us at:

repository@maastrichtuniversity.nl

providing details and we will investigate your claim.
}

Copyright and moral rights for the publications made accessible in the public portal are retained by the authors and/or other copyright owners and it is a condition of accessing publications that users recognise and abide by the legal requirements associated with these

- Users may download and print one copy of any publication from the public portal for the purpose of private study or research.

- You may not further distribute the material or use it for any profit-making activity or commercial gain

If the publication is distributed under the terms of Article $25 \mathrm{fa}$ of the Dutch Copyright Act, indicated by the "Taverne" license above, 


\title{
Seasonal and long-run fractional integration in the Industrial Production Indexes of some Latin American countries
}

\author{
B. Candelon ${ }^{\text {a }}$, L.A. Gil-Alana ${ }^{b, *}$ \\ ${ }^{a}$ University of Maastricht, Maastricht, The Netherlands \\ ${ }^{\mathrm{b}}$ Facultad Ciencias Economicas, Universidad de Navarra, Edificio Biblioteca, \\ Entrada Este, E-31080 Pamplona, Spain
}

Received 6 June 2003; received in revised form 2 February 2004; accepted 22 March 2004

Available online 20 April 2004

\begin{abstract}
In this article we propose a new approach that permits us to simultaneously test unit and fractional roots at the long-run and the seasonal frequencies. We examine the Industrial Production Indexes (IPI) in four Latin American countries (Brazil, Argentina, Colombia and Mexico), using new statistical tools based on seasonal and non-seasonal long-memory processes. Results show that the root at the long-run or zero frequency plays a much more important role than the seasonal one. Nevertheless, in the cases of Brazil and Argentina a component of long memory behaviour is also present at the seasonal structure, indicating that shocks modify the seasonal structure for a long period. Policy makers should thus pay attention to this result in choosing the optimal economic policy.

(C) 2004 Society for Policy Modeling. Published by Elsevier Inc. All rights reserved.
\end{abstract}

JEL classification: $\mathrm{C} 22$

Keywords: Fractional integration; Seasonality; Long memory

\section{Introduction}

The recent economic literature has stressed two major characteristics of macroeconomic series which has been used by academics or economic advisers to better

\footnotetext{
* Corresponding author. Tel.: +34-948-425625; fax: +34-948-425626.
}

E-mail address: alana@unav.es (L.A. Gil-Alana). 
understand the consequences of economic policies. First, since the seminal paper of Nelson and Plosser (1982), it appears that almost all series possess a unit root. The consequences of the presence of a stochastic trend are major for the modelling and the decision of economic policies, as a shock affecting one of these series will be persistent and will never die out. The second stylized fact is the presence of seasonal components. Traditionally, seasonal fluctuations have been considered as a nuisance that shadows the most important components of the series (namely the growth and the business cyclical components, e.g., Burns \& Mitchell, 1946). They are often removed beforehand via seasonal adjustment procedures. Thus, most of the empirical works considers simply seasonally adjusted data, without paying attention to the role of seasonality. A lot of papers have stressed on one of these two features, but only a few have been concerned with the linkages between the seasonal and the long-run structures.

Hasza and Fuller (1982) have shown that seasonal adjustment biases traditional unit root tests. Such errors are very difficult to measure and so to correct by systematic procedures. Nevertheless, the consequences for political advisors are strong as the persistence of shocks are not correctly determined, leading to misperception in the consequences of economic policies. Moreover, seasonal adjustment procedures do not generally take into account the possible fractional roots at seasonal frequencies, leading thus to erroneous conclusions about its behaviour. For example, a structural economic policy (aiming at modifying the long-run behaviour) may induce a persistent modification of the seasonal structure, ruling out the initial objectives.

In this article we develop a new framework allowing for unit and fractional roots simultaneously at zero (long-run) and the seasonal frequencies. It constitutes an alternative to test for (fractional) unit roots without using any prior seasonal adjustment. It is based on fractionally integrated techniques. To illustrate our theoretical concept, we analyse the monthly structure of several Industrial Production Indexes (IPI) in some Latin American countries. The results suggest that the series can be well characterized in terms of $I(d)$ processes with roots at both at the zero and the seasonal (monthly) frequencies. The structure of the paper is as follows: Section 2 briefly describes a model that incorporates seasonal and non-seasonal roots. Section 3 presents a version of the tests of Robinson (1994) that permits us to test this type of model. In Section 4, the tests are applied to IPI series, while Section 5 contains some concluding comments.

\section{A model with seasonal and non-seasonal unit and fractional roots}

It is a well-known fact that many time series contain important seasonal components and seasonal first differences is the easiest way to remove the seasonal component. Dickey, Hasza, and Fuller (DHF, 1984); Hylleberg, Engle, Granger, and Yoo (HEGY, 1990), Beaulieu and Miron (1993) and Tam and Reimsel (1997), amongst others proposed test statistics to eliminate the seasonal unit roots in raw 
time series. Thus, for example, if $x_{t}$ is the time series we observe, with a seasonal changing pattern, we can consider the model,

$$
\left(1-L^{s}\right) x_{t}=u_{t}, \quad t=1,2, \ldots,
$$

where $L^{s}$ is the seasonal lag operator $\left(L^{s} x_{t}=x_{t-s}\right) ; s$ is the number of time periods in a year, and where $u_{t}$ is an $I(0)$ process, defined as a covariance stationary process with positive and finite spectral density function at any frequency of the spectrum. Note that the polynomial in (1) can be decomposed into:

$$
(1-L)\left(1+L+L^{2}+\cdots+L^{s-1}\right)=(1-L) S(L) .
$$

That is, the seasonal difference operator can be broken down into the product of the first difference operator and the moving-average filter $S(L)$, containing further roots of modulus unity. Therefore, the root at the zero frequency appears as a component of the seasonal polynomial in (1). However, there are many cases where this frequency plays a major role, describing not only part of the seasonal structure but also the trending stochastic behaviour of the series. In fact, Hasza and Fuller (1982) consider the model:

$$
(1-L)\left(1-L^{s}\right) x_{t}=u_{t}, \quad t=1,2, \ldots,
$$

where the first polynomial in (3) represents a stochastic trend, while the second indicates a seasonal structure. In their unit-root test, they suggest to estimate the equations:

$$
\begin{aligned}
& x_{t}=\alpha_{1} x_{t-1}+\alpha_{2} x_{t-s}+\alpha_{3} x_{t-s-1}+u_{t}, \\
& x_{t}=\phi_{1} x_{t-1}+\phi_{2}\left(x_{t-s}-\phi_{1} x_{t-s-1}\right)+u_{t},
\end{aligned}
$$

and then to test the restrictions $\left[\alpha_{1}, \alpha_{2}, \alpha_{3}\right]=[1,1,-1]$ or $\left[\phi_{1}, \phi_{2}\right]=[1,1]$ with a standard $F$-statistic and using the proper tabulated distributions. Dickey and Pantula (1987) pointed out, however, the inappropriateness of such tests since they are two sided in nature whereas the alternative of stationarity is one-sided.

In this article we generalize the model in the above unit-root test to allow for fractional roots at zero and the seasonal frequencies. Besides, using the LM-based testing procedure developed by Robinson (1994), the tests are the most powerful ones when directed against the appropriate (fractional) alternatives, and due to the use of the latter alternatives, free of the Dickey and Pantula's (1987) criticism. Robinson's (1994) tests have also the advantage of being pivotal, and so finite-sample size distortions can easily be corrected by re-sampling methods such as bootstrap (see, e.g., Candelon \& Gil-Alana, 2003).

Hence, model (3) can be viewed as a particular case of a much more general type of long memory processes, allowing fractional roots at zero and the seasonal frequencies of form:

$$
(1-L)^{d_{1}}\left(1-L^{s}\right)^{d_{2}} x_{t}=u_{t}, \quad t=1,2, \ldots,
$$


for given real values $d_{1}$ and $d_{2}$. Here, the first fractional polynomial can be expressed in terms of its binomial expansion such that for all real $d_{1}$,

$$
(1-L)^{d_{1}}=\sum_{j=0}^{\infty}\left(\begin{array}{c}
d_{1} \\
j
\end{array}\right)(-1)^{j} L^{j}=1-d_{1} L+\frac{d_{1}\left(d_{1}-1\right)}{2} L^{2}-\cdots
$$

and similarly for the seasonal structure,

$$
\left(1-L^{s}\right)^{d_{2}}=\sum_{j=0}^{\infty}\left(\begin{array}{c}
d_{2} \\
j
\end{array}\right)(-1)^{j} L^{s j}=1-d_{2} L^{s}+\frac{d_{2}\left(d_{2}-1\right)}{2} L^{2 s}-\cdots
$$

Clearly, imposing $d_{1}=0$ and $d_{2}=1$, (4) becomes the seasonal unit root model (1) proposed by Hasza and Fuller (1982), and, imposing $d_{1}=d_{2}=1$, we obtain (3). Let us consider first the case of $d_{2}=0$. In this context, if $d_{1}>0, x_{t}$ is said to be a long memory process (at the long-run frequency), so-called because of the strong association between observations widely separated in time. In such a case, the series does not exhibit seasonal movement. The long-run effect of shocks is then crucial for the global dynamic of the process. Similarly, imposing $d_{1}=0$, the model in (4) becomes:

$$
\left(1-L^{s}\right)^{d_{2}} x_{t}=u_{t}, \quad t=1,2, \ldots
$$

and if $d_{2}>0$, it is called a seasonally fractionally integrated (or seasonal long memory) process. In such a case, the seasonal dynamics are of major importance for the behaviour of the series. Extreme cases appear when $d_{2}>1$. Several studies have explored this topic (see Gil-Alana \& Robinson, 2001; Porter Hudak, 1990 inter alia). However, there are not so far empirical works that simultaneously test the degrees of integration at zero and the seasonal frequencies and, in that respect, the present paper considers the general model (4), allowing for simultaneous seasonal and non-seasonal unit and fractional roots, at the same time, trying of being an alternative credible approach to the traditional models based on (1) or (3). This approach constitutes a new framework for empirical analyses with seasonal data. It leads to an unbiased estimation of the degree of the seasonal and the long-run fractional integration. Thus, economics advisers are able to discriminate the optimal economic policy.

\section{The testing procedure}

Robinson (1994) proposes a Lagrange Multiplier (LM) test of the null hypothesis:

$$
H_{\mathrm{o}}: d=\left(d_{1}, d_{2}\right)^{\prime}=\left(d_{1 \mathrm{o}}, d_{2 \mathrm{o}}\right)^{\prime}=d_{\mathrm{o}}
$$


in a model given by (4), for any given real numbers $d_{10}$ and $d_{20}$. For the ease of presentation, we consider monthly data, and then assume in the sequel of the paper $s=12$. Specifically, the test statistic is given by:

$$
\hat{R}=\frac{T}{\hat{\sigma}^{4}} \hat{a}^{\prime} \hat{A}^{-1} \hat{a}
$$

where $T$ is the sample size, and

$$
\begin{aligned}
& \hat{a}=\frac{-2 \pi}{T} \sum_{j}^{*} \psi\left(\lambda_{j}\right) g\left(\lambda_{j} ; \hat{\tau}\right)^{-1} I\left(\lambda_{j}\right) ; \quad \hat{\sigma}^{2}=\sigma^{2}(\hat{\tau})=\frac{2 \pi}{T} \sum_{j=1}^{T-1} g\left(\lambda_{j} ; \hat{\tau}\right)^{-1} I\left(\lambda_{j}\right), \\
& \hat{A}=\frac{2}{T}\left(\sum_{j}^{*} \psi\left(\lambda_{j}\right) \psi\left(\lambda_{j}\right)^{\prime}-\sum_{j}^{*} \psi\left(\lambda_{j}\right) \hat{\varepsilon}\left(\lambda_{j}\right)^{\prime}\left(\sum_{j}^{*} \hat{\varepsilon}\left(\lambda_{j}\right) \hat{\varepsilon}\left(\lambda_{j}\right)^{\prime}\right)^{-1}\right. \\
& \left.\times \sum_{j}^{*} \hat{\varepsilon}\left(\lambda_{j}\right) \psi\left(\lambda_{j}\right)^{\prime}\right) \\
& \psi\left(\lambda_{j}\right)^{\prime}=\left[\psi_{1}\left(\lambda_{j}\right), \psi_{2}\left(\lambda_{j}\right)\right] ; \quad \hat{\varepsilon}\left(\lambda_{j}\right)=\frac{\partial}{\partial \tau} \log g\left(\lambda_{j} ; \hat{\tau}\right) ; \\
& \psi_{1}\left(\lambda_{j}\right)=\log \left|2 \sin \frac{\lambda_{j}}{2}\right| \text {; } \\
& \psi_{2}\left(\lambda_{j}\right)=\log \left|2 \sin \frac{\lambda_{j}}{2}\right|+\log \left(2 \cos \frac{\lambda_{j}}{2}\right)+\log \left|2 \cos \lambda_{j}\right| \\
& +\log \left|2\left(\cos \lambda_{j}-\cos \frac{\pi}{3}\right)\right|+\log \left|2\left(\cos \lambda_{j}-\cos \frac{2 \pi}{3}\right)\right| \\
& +\log \left|2\left(\cos \lambda_{j}-\cos \frac{\pi}{6}\right)\right|+\log \left|2\left(\cos \lambda_{j}-\cos \frac{5 \pi}{6}\right)\right|,
\end{aligned}
$$

with $\lambda_{j}=2 \pi j / T . I\left(\lambda_{j}\right)$ is the periodogram of $\hat{u}_{t}=(1-L)^{d_{1 o}}\left(1-L^{12}\right)^{d_{2 o}} x_{t}$, and $\hat{\tau}=\arg \min _{\tau \in T^{*}} \sigma^{2}(\tau)$ with $T^{*}$ as a compact subset of the $R^{q}$ Euclidean space. The function $g$ above is known and comes from the spectral density of $u_{t}$ :

$$
f(\lambda ; \tau)=\frac{\sigma^{2}}{2 \pi} g(\lambda ; \tau), \quad-\pi<\lambda \leq \pi,
$$

and the summation on $\left(^{*}\right)$ in the above expressions refers to the discrete bounded frequencies $\lambda_{j}$.

Based on $H_{0}$ (6), Robinson (1994) established that, under certain regularity conditions:

$$
\hat{R} \rightarrow_{d} \quad \chi_{2}^{2}, \quad \text { as } \quad T \rightarrow \infty .
$$


Thus, unlike other procedures, we are in a classical large-sample testing situation by reasons described in Robinson (1994), who also showed that the tests are efficient in the Pitman sense against local departures from the null. A test of (6) will reject $\mathrm{H}_{\mathrm{o}}$ against the alternative $\mathrm{H}_{\mathrm{a}}: d \neq d_{\mathrm{o}}$ if $\hat{R}>\chi_{2, \alpha}^{2}$, where Prob $\left(\chi_{2, \alpha}^{2}>\chi_{2}^{2}\right)=\alpha$.

\section{An application to industrial production index in Latin American countries}

The time series data used in this section correspond to the log-transformation of the monthly structure of the Industrial Production Indexes series in Brazil, Mexico, Colombia and Argentina, obtained from the IFS database of the International Monetary Fund. These series are seasonally unadjusted. The starting date is January 1980 for Brazil and Mexico, January 1985 for Argentina, and January 1986 for Colombia, and all series end in November-2001.

Fig. 1 contains plots of the original series with their corresponding correlograms and periodograms. The series have a non-stationary appearance and the correlograms clearly show a seasonal pattern, especially for Brazil and Colombia, though a visual inspection at the periodograms also indicates the importance of the root at the long-run frequency. Similar plots for the first differenced data are given in Fig. 2, and the seasonal component, revealed by the 11 peaks in the periodogram, becomes apparent in all cases. Finally, the plots of first and first seasonal (monthly) differences are displayed in Fig. 3, and the correlograms and the periodograms in this figure suggest that the series might now be overdifferenced with respect to both, the zero and the seasonal frequencies.

Denoting the time series by $x_{t}$, we employ throughout model (4), testing $\mathrm{H}_{\mathrm{o}}$ (6) for values $d_{1 \mathrm{o}}, d_{2 \mathrm{o}}=0,(0.25), 2$, including thus tests for a unit root exclusively at the long-run (zero frequency) $\left(d_{1 \mathrm{o}}=1, d_{2 \mathrm{o}}=0\right)$; tests for seasonal unit roots $\left(d_{1 \mathrm{o}}=0, d_{2 \mathrm{o}}=1\right)$; unit and seasonal unit roots $\left(d_{1 \mathrm{o}}=d_{2 \mathrm{o}}=1\right)$; as well as other fractionally integrated possibilities. We assume that $u_{t}$ is white noise, and though not reported in the paper, we also consider the case of autocorrelated disturbances, in particular, $\mathrm{AR}(1)$ and seasonally monthly $\mathrm{AR}(1)$ processes.

The test statistic reported across Table 1 is the one given by $\hat{R}$ in (7). However, instead of presenting the results for all values of $d_{10}$ and $d_{2 o}$, we just report across the tables those cases where we find at least one non-rejection value for each country. We observe that $\mathrm{H}_{\mathrm{o}}(6)$ cannot be rejected for any series when $\left(d_{1 \mathrm{o}}, d_{2 \mathrm{o}}\right)=$ $(0.00,1.00)$, implying that a seasonal unit root with white noise $u_{t}$ may be a plausible way of modelling the series. However, apart from this case, all the remaining non-rejection values take place when $d_{10}=1,1.25,1.50$ and 1.75 with $d_{2 \mathrm{o}}=0$ or 0.25 . Thus, we observe higher degrees of integration at the long-run frequency than at the seasonal ones. Some differences appear across countries. More non-rejections are observed for Brazil and Argentina than for Colombia and Mexico. In fact, $\mathrm{H}_{\mathrm{o}}(6)$ cannot be rejected when $d_{10}=1,1.25,1.50$ and 1.75, with $d_{2 \mathrm{o}}=0.25$ for Brazil and Argentina, these hypotheses being rejected for the 


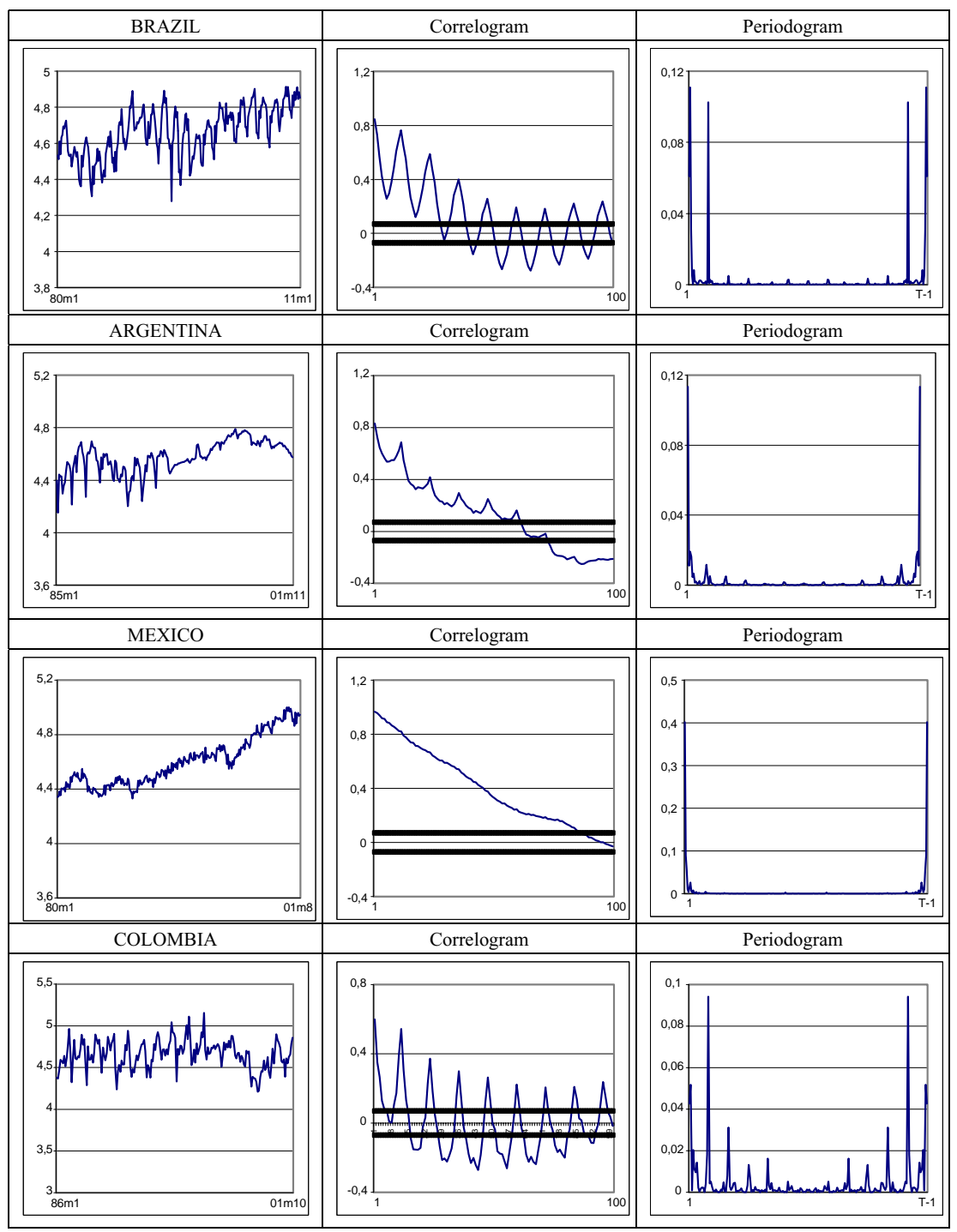

Fig. 1. Log of the Industrial Production Indexes (IPI), with their corresponding correlograms and periodograms. The large-sample standard error under the null hypothesis of no autocorrelation is $1 / T^{1 / 2}$ or roughly 0.07 for series of length considered here.

remaining two countries. Thus, it turns out that models with fractional roots at seasonal frequencies are more rejected for Colombia and Mexico than for Brazil and Argentina, implying that the seasonal structure appears more important for these two later countries. Such a result indicates that seasonal shocks are more persistent in Brazil and Argentina than in Mexico or Colombia. 


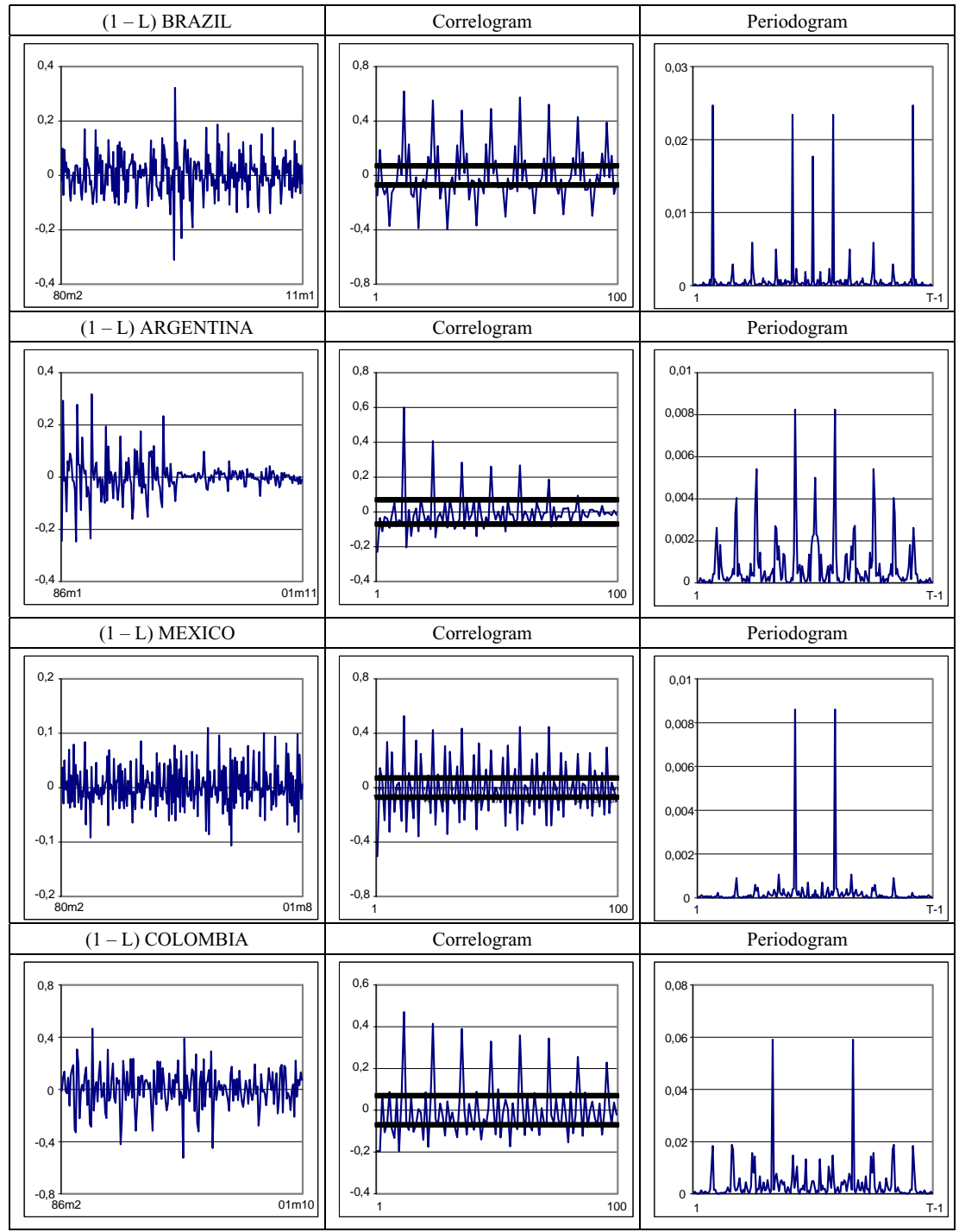

Fig. 2. First differences of the IPI, with their corresponding correlograms and periodograms. The large-sample standard error under the null hypothesis of no autocorrelation is $1 / T^{1 / 2}$ or roughly 0.07 for series of length considered here.

In order to have a more precise view about the message contained in this table, we have performed the same tests, but this time using increments for $d_{1 \mathrm{o}}$ and $d_{2 \mathrm{o}}$ of 0.01 . Fig. 4 displays the non-rejection regions for each country. We see that $d_{1 \mathrm{o}}$ is in all cases higher than $d_{2 \mathrm{o}}$, stressing once more the importance of the root at zero 


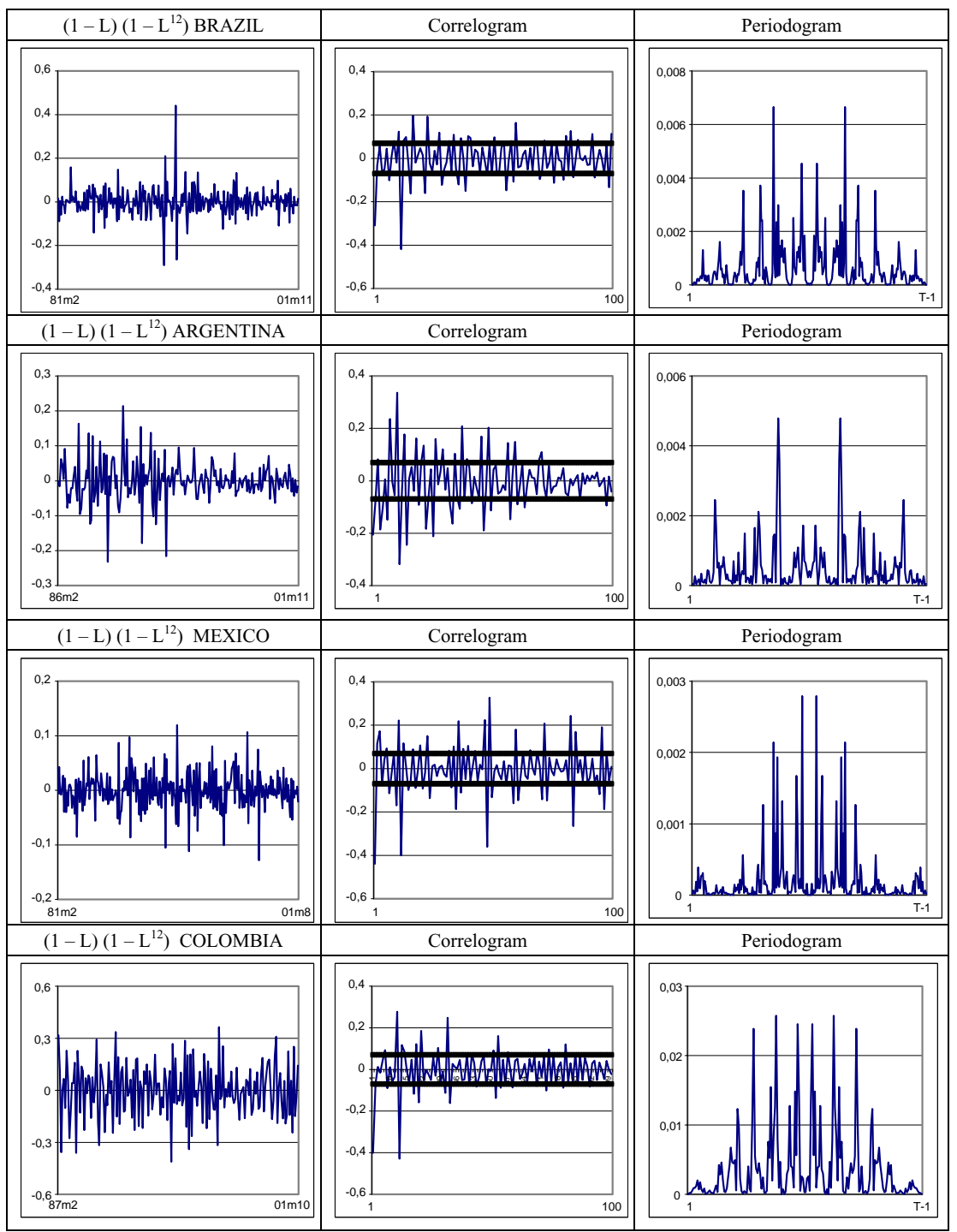

Fig. 3. First and first seasonal differences of the IPI, with their corresponding correlograms and periodograms. The large-sample standard error under the null hypothesis of no autocorrelation is $1 / T^{1 / 2}$ or roughly 0.07 for series of length considered here.

over the seasonal ones. Also, the fact that $d_{1}$ is in all cases higher than 0.5 indicates that the component corresponding to the zero frequency is clearly non-stationary. On the other hand, we observe that $d_{2}$ is always strictly smaller than 0.5 , suggesting that, if the long-run trend is considered, the seasonal structure is stationary though 
Table 1

Testing $\mathrm{H}_{\mathrm{o}}$ (6) in (4) with the tests of Robinson (1994) and whitenoise disturbances

\begin{tabular}{llllrr}
\hline$d_{1 \mathrm{o}}$ & $d_{20}$ & Brasil & Argentina & Mexico & Colombia \\
\hline 0.00 & 1.00 & $\mathbf{1 . 0 1 1}$ & $\mathbf{0 . 6 4 6}$ & $\mathbf{1 . 2 1 3}$ & $\mathbf{3 . 3 2 5}$ \\
0.75 & 0.00 & $\mathbf{0 . 3 5 8}$ & $\mathbf{0 . 4 4 4}$ & $\mathbf{0 . 7 2 3}$ & $\mathbf{1 . 9 3 6}$ \\
0.75 & 0.25 & $\mathbf{4 . 1 0 5}$ & $\mathbf{3 . 3 3 0}$ & $\mathbf{5 . 7 5 1}$ & $\mathbf{5 . 5 2 8}$ \\
1.00 & 0.00 & $\mathbf{0 . 5 2 7}$ & $\mathbf{0 . 6 5 6}$ & $\mathbf{1 . 2 7 6}$ & $\mathbf{2 . 7 2 8}$ \\
1.00 & 0.25 & $\mathbf{4 . 9 0 5}$ & $\mathbf{4 . 0 2 6}$ & 8.089 & 8.119 \\
1.25 & 0.00 & $\mathbf{0 . 3 4 8}$ & $\mathbf{0 . 6 5 3}$ & $\mathbf{1 . 4 1 8}$ & $\mathbf{2 . 8 3 5}$ \\
1.25 & 0.25 & $\mathbf{4 . 8 7 4}$ & $\mathbf{4 . 2 3 2}$ & 10.943 & 9.004 \\
1.50 & 0.00 & $\mathbf{0 . 1 8 3}$ & $\mathbf{0 . 5 5 5}$ & $\mathbf{1 . 3 8 9}$ & $\mathbf{2 . 5 6 0}$ \\
1.50 & 0.25 & $\mathbf{4 . 3 4 3}$ & $\mathbf{4 . 0 5 2}$ & 8.885 & 13.243 \\
1.75 & 0.00 & $\mathbf{0 . 2 4 2}$ & $\mathbf{0 . 4 3 8}$ & $\mathbf{1 . 3 2 0}$ & $\mathbf{2 . 2 1 0}$ \\
1.75 & 0.25 & $\mathbf{3 . 3 6 5}$ & $\mathbf{3 . 6 5 5}$ & 10.045 & $\mathbf{5 . 2 9 7}$ \\
1.75 & 0.50 & 7.654 & $\mathbf{5 . 9 6 4}$ & 13.214 & 11.345 \\
\hline
\end{tabular}

In bold, the non-rejection values at the $95 \%$ significance level.

with a component of long memory behaviour. It should also be noted that though the tests are unable to reject the null when $d_{2 \mathrm{o}}=0$, i.e., with no seasonal fractional roots, these hypotheses are in all cases "less clearly non-rejected"1 than when $d_{20}$ is positive, suggesting that a component of long memory is present in relation with the seasonal part.

These results have thus strong implications in terms of economic policy and planning inference. A particular shock will simultaneously affect the seasonal and the long-run structure of the IPI. Nevertheless, shocks will be mean reverting for the seasonal structure (i.e., their effects disappear in the long-run), whereas the effect will persist on the long-run structure. Thus, a structural economic policy, aiming at modifying the long-run properties of the IPI, can be run out without paying too much attention on the effects on the seasonal structure, as they will quickly die out. Nevertheless, this policy advice has to be modulated for Brazil and Argentina, where the seasonal fractional root is found to lie between 0.3 and 0.6. In these cases, even if shocks are shown to be mean reverting for the seasonal structure, they posses long memory. It means that an economic policy will have a long-run effect and will take time before dying out. Hence, if a structural economic policy is performed in Brazil and Argentina, it will induce a modification of the seasonal structure of the IPI. These effects will not be permanent (the unit-root hypothesis at seasonal frequencies is rejected) but very long lasting. Particular attention should thus be paid to seasonal effects of economic policies in Brazil and Argentina, which is not the case for Colombia and Mexico.

We also performed the tests for the case of autocorrelated disturbances and the results were similar in both cases and also similar to those given in Table 1. Thus,

\footnotetext{
${ }^{1}$ By 'less clearly non-rejected', we mean that the value of the test statistic is closer to the rejection values.
} 


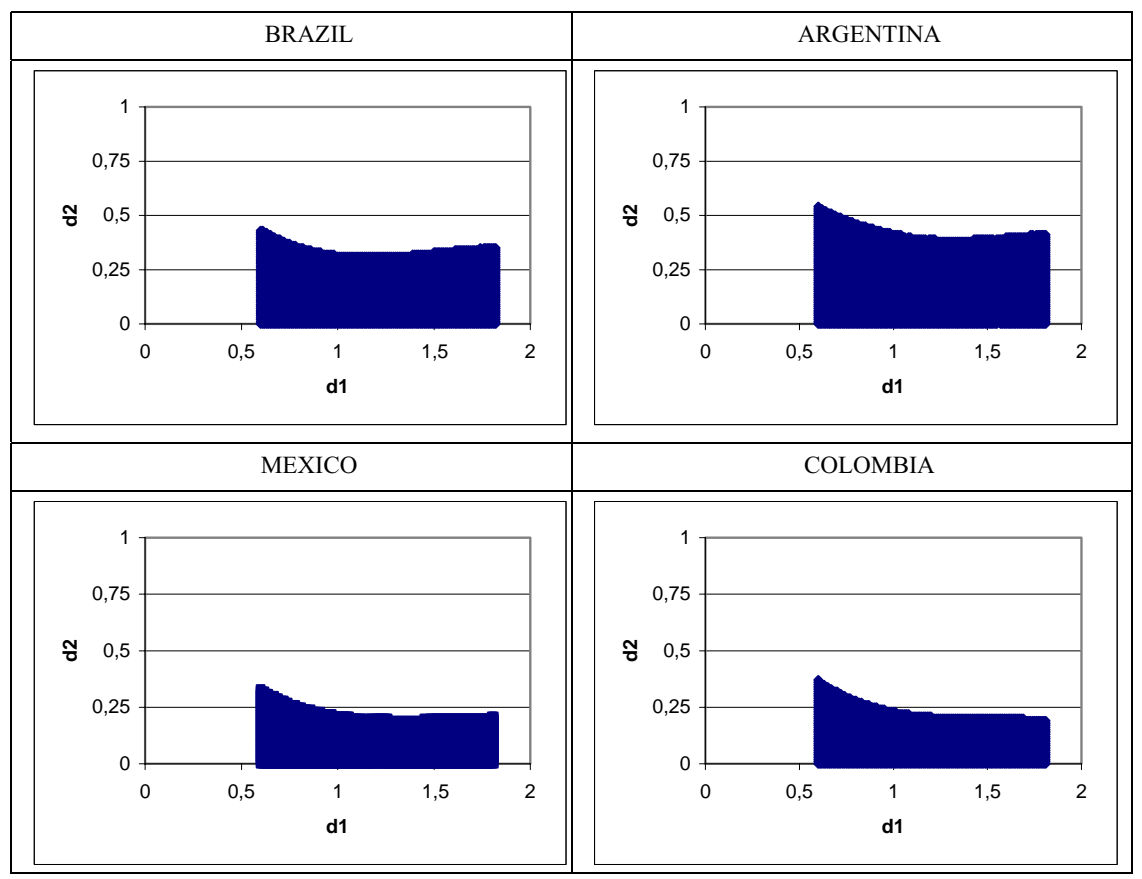

Fig. 4. Regions of values of $d_{1 \mathrm{o}}$ and $d_{2 \mathrm{o}}$ where $\mathrm{H}_{\mathrm{o}}$ (6) cannot be rejected at the $95 \%$ significance level.

apart from the case of $\left(d_{10}, d_{20}\right)=(0,1)$, all the other non-rejection values take place when $d_{1 \mathrm{o}}$ is between 0.75 and 1.75 with $d_{2 \mathrm{o}}=0$ or 0.25 .

The results presented across this paper present some ambiguous conclusions. Thus, on the one hand, the seasonal unit root model cannot be rejected for any series and any type of disturbances. On the other hand, most of the non-rejections occur when $d_{10}$ is between 0.75 and 1.75 with $d_{20}=0$ or 0.25 . This may be explained by the fact that the tests of Robinson (1994), when integer values of $d_{10}$ and $d_{2 o}$ are entertained, have low power to detect fractional models. In fact, we made several Monte Carlo experiments, conducting the tests with $\left(d_{10}, d_{2 \mathrm{o}}\right)=(0,1)$ on fractional series with $d_{1}=1,1.25,1.50$ and 1.75, and $d_{2}=0$ and 0.25 , and the rejection frequencies of the tests never exceeded 0.400 . On the other hand, performing the tests with $d_{1 \mathrm{o}} \in[0.75,1.75]$ and $d_{2 \mathrm{o}} \in[0,0.25]$ on purely seasonal unit-root models, the rejection probabilities were practically 1 in all cases for series of length considered here. In view of this, we can conclude by saying that the non-rejections obtained for the seasonal unit-root model are perhaps spurious and due to the low power of this version of the tests for testing integer differences when fractional models are entertained. 


\section{Concluding comments}

In this article we have examined the monthly structure of the log-transformation of the Industrial Production Indexes in several Latin American countries by means of a version of the tests of Robinson (1994) that permits us to simultaneously test the degrees of integration at zero and the seasonal monthly frequencies. These tests have standard null and local limit distributions and several experiments conducted via Monte Carlo show that the tests perform relatively well in finite samples. The results show that the long-run or zero frequency plays a crucial role when modelling the time series behaviour of the series, with an order of integration ranging between 0.75 and 1.75 , though the seasonal root should also be incorporated in the model, with an order of integration ranging between 0 and 0.5 for Argentina and Brazil, and slightly smaller for the other two countries. The presence of the fractional seasonal roots will affect the conclusions obtained by classical unit-root tests.

Policy advices can be drawn from this model as our new framework helps to better characterize the mean reverting properties of the series at seasonal and zero frequencies. Applying it to the IPI in four Latin American countries, it turns out that long-run effects of shocks might not be mean reverting, indicating the importance of long-run effect of economic policies. It is also noticeable that seasonal fluctuations have shorter memory in Colombia and Mexico than in Brazil and Argentina. For these last two countries, policy makers should pay a particular attention at the seasonal effect of the shocks, as they take time before dying out.

\section{Acknowledgments}

Financial support of METEOR through the project "Macroeconomic consequences of financial crisis" is gratefully acknowledged. This work has been performed during the visit of L.A. Gil-Alana at the Economics Department of the University of Maastricht, throughout the Grant B 46-498 of the Nederlandse Organisatie voor Wetenschappelijk Onderzoek. Errors and omissions remain ours.

\section{References}

Beaulieu, J. J., \& Miron, J. A. (1993). Seasonal unit roots in aggregate U.S. data. Journal of Econometrics, 55, 305-328.

Burns, A. F., \& Mitchell, W. C. (1946). Measuring business cycles. National Bureau of Economic Research, New York, NY, USA.

Candelon, B., \& Gil-Alana, L. A. (2003). On finite sample critical values of the tests of Robinson (1994) for fractional integration. Journal of Statistical Computation and Simulation, 73, 445-464.

Dickey, D. A., Hasza, D. P., \& Fuller, W. A. (1984). Testing for unit roots in seasonal time series. Journal of the American Statistical Association, 79, 355-367.

Dickey, D. A., \& Pantula, S. G. (1987). Determining the order of differencing in autoregressive processes. Journal of Business and Economic Statistics, 5, 455-461. 
Gil-Alana, L. A., \& Robinson, P. M. (2001). Testing seasonal fractional integration in the UK and Japanese consumption and income. Journal of Applied Econometrics, 16, 95-114.

Hasza, D. P., \& Fuller, W. A. (1982). Testing for nonstationary parameter specifications in seasonal time series models. Annals of Statistics, 10, 1209-1216.

Hylleberg, S., Engle, R. F., Granger, C. W. J., \& Yoo, B. S. (1990). Seasonal integration and cointegration. Journal of Econometrics, 44, 215-238.

Nelson, C. R., \& Plosser, C. I. (1982). Trends and random walks in macroeconomic time series. Journal of Monetary Economics, 10, 139-162.

Porter Hudak, S. (1990). An application of the seasonal fractionally differenced model to the monetary aggregates. Journal of the American Statistical Association, 85(410), 338-344.

Robinson, P. M. (1994). Efficient tests of nonstationary hypotheses. Journal of the American Statistical Association, 89, 1420-1437.

Tam, W., \& Reimsel, G. C. (1997). Tests for seasonal moving average unit root in ARIMA models. Journal of the American Statistical Association, 92, 725-738. 